\section{The limits to growth}

\section{Some implications for forestry}

\section{E. S. TELFER}

Canadian Wildlife Service Edmonton, Alberta

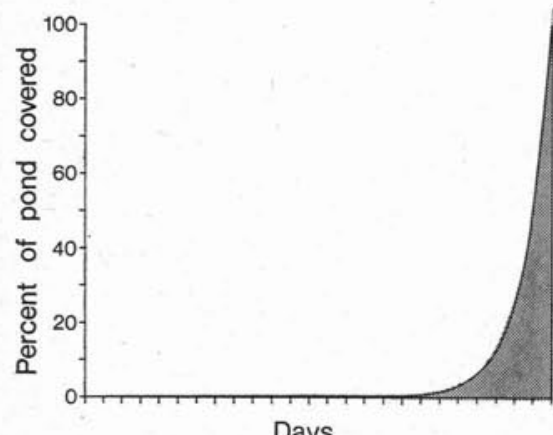

Fig. 1. An example of exponential growth from an old French folk tale. The area of a pond covered by pondweeds doubles each day, but it is only in the last few days that the situation appears serious.
The winter of 1973-74 will go down in history as the winter of the first oil crisis. Perhaps the most important aspect of the crisis is that for the first time the majority of people in the Western World have been forced to realize that the resources available to them are not limitless. This, of course, is no news to ecologists, who have been pointing out the rather shaky resource base of the industrialized world for at least two decades. In recent years alarm over sky-rocketing use of resources coupled with ominous increases in pollution and in human population has been sounded in many quarters. One of the outstanding descriptions of the outlook for industrial man has been presented not by ecologists but by an elite international group of executives and academics known as the Club of Rome. The concern of these individuals led to support for a group of researchers at the Massachusetts Institute of Technology (MIT) who applied systems analysis techniques and computer simulation to project the future course of human affairs.

The results of the MIT studies have been presented in a nontechnical book, The Limits to Growth (Meadows et al. 1972), that is having an immense influence on popular thinking on resources. Since the ideas presented in the book have as yet received little attention in forestry literature, it seems worthwhile to explore the impact of the Club of Rome's findings upon our professional concerns.

\section{The limits to growth}

MIT researchers emphasize two main points: that resources have limits, and that our approach to those limits has been at an exponential rate. The book noted that many features of the world system such as living space, the amount of pollution the system can absorb, the amount of food that can be produced, and the amount of mineral resources available have ultimate limitations. We can make estimates of what those limits are in many cases. For instance, the amount of petroleum in reserves, and the amount that may still be found can be reasonably well predicted based on past exploration experience.

Many components of the world system are approaching these ultimate resource limits at an exponential rate. The authors use an old French folktale as an example of exponential growth. In the story a man owned a beautiful pond that was being covered gradually by pond weeds. The rate of growth of pond weeds was such that the area covered by them doubled every day. For a long time this did not appear to be doing much harm, but one day the entire pond was choked with weeds. An interesting point was that, with exponential growth, one day before disaster, only $50 \%$ of the pond's area was covered with weeds (Fig. 1).

The key to understanding our resource scarcity problems is to understand exponential growth. There are many examples to be derived from statistics on the world system. Population, use of energy, demand for food and utilization of non-renewable resources such as metals have been growing at an exponential rate.

The MIT systems analysts constructed models using the best information that they could obtain on population growth, resource use and the amount of available materials, and then ran simulation studies on these models to see what would happen with various assumptions of resources and technology. In almost every case the models suggested that population, industrialization and pollution would overshoot the capacity of the world system, leading to a catastrophic decline in population and per capita output during the coming century. One of the most surprising aspects of the simulation was that even by drastically increasing the values assigned to the technological capabilities of mankind, economic collapse, due to lack of food and accumulating pollution, could only be postponed by a very few decades. The awesome capacity for increase inherent in exponential growth was thus made apparent. Foresters who have calculated the astounding level to which planting costs can rise 
when computed at compound interest over a rotation can readily appreciate the problem.

The findings of the Club of Rome's project were as startling and uncomfortable to the researchers as they subsequently proved to be to others. The MIT researchers have published their models, along with their assumptions of values to be assigned to terms in the models, in many scientific publications, and begged experts in all fields to examine the models critically. Thus, improvements might be suggested both in the structure of the models and in the data used to derive values for the terms. The researchers were well aware of the hazards of attempting to simulate the world system by a comparatively simple model. Their model assumes a peaceful and economically unified world. They did not try to assess the impact of social change or economic nationalism. Changes in social values and organization may be either helpful or harmful and are the most potent unknown quantities in the system.

One critical area where information is lacking is the impact of pollution on man. It is assumed by the MIT group that at some point pollution of air, water, and landscape will cause human mortality on a large scale, either directly or indirectly. However, information is sketchy, as is information on the amounts and types of pollution likely to be produced by our escalating technology, and the capacity of the world's atmosphere, land and water to absorb pollution.

It is, in fact, the pollution model that has been most seriously criticized by other scientists. Boyle (1973) reports finding an error in the model that caused an over-estimate of the effect of pollution. $\mathrm{He}$ adjusted for the error and produced simulations suggesting that pollution might be controlled by advancing technology until improved methods of birth control stabilized world population at 6 billion. However, Boyle worked with an optimistic set of assumptions about resource availability and technological innovation. Although his corrected model showed the same pattern of decline in resources, in food and in industrial output per capita, Boyle suggested that the world system could be stabilized by less drastic economic and social measures than those suggested in The Limits to Growth.

Another report containing an authoritative documentation of the world's resources and the probable course of their exploitation has been made by the Committee on Resources and Man of the National Academy of Science and the National Research Council (of the United States) (1969). The Committee's review led it to conclusions similar to those of the MIT researchers.

The MIT group ran a series of computer simulations in which they introduced population stabilization (by assuming that numbers of births and deaths would be equal), restrictions on investment in industry, and various levels of technological change. They further varied the year of introduction of such measures. The set of assumptions that gave a combination of stability and decent living standards included: immediate stabilization of world population and no increase in industrial capital after
1990; reduction of resource depletion and pollution by industrial processes to one quarter of present values per unit of output; some shift of capital to food production, especially to soil conservation; building capital goods to last longer, and encouragement of people to shift their consumption from goods to services.

The researchers point out that within the limits required to maintain an equilibrium state, technological change would be necessary and desirable. Furthermore, they quote John Stuart Mill to the effect that: ". . . a stationary condition of capital and population implies no stationary state of human improvement". They point out that different societies would prefer different relative levels of various goods and services and of regional population distributions. Many of the more humane aspects of human culture - education, art, music, athletics, scientific research, religion and social interactions - would be free to develop in an equilibrium economic state. In fact, freedom from the pressures of forced economic growth could well result in a flowering of such activities. Creation of such a desirable state of affairs would require a definite national policy, otherwise the gloomy view of the editor of Nature (Vol. 246 No. 5434:VII) that "nogrowth" would mean drastic reduction in scientific and cultural opportunities would be realized.

\section{Implications for forestry}

Wood as a raw material. In an environmentally conscious age facing resource scarcity, wood has many advantages as a raw material. Wood, from productive sites, is a renewable resource; it can be converted to useable products with a small amount of energy (compare, for instance, the energy required to produce a wooden beam and one made of aluminum); wood is biodegradable, if you throw a piece away it will rot; wood can be burned without putting any unnatural substance into air or water resources (although combustion adds carbon dioxide to that from other sources); it can be recycled, in fact paper is one of the few commodities which has regularly been recycled, apparently profitably, even in our throw-away economy. Wood, both new and in recycled form, can be converted into a vast variety of useful products for construction, for clothing and other fibre uses, for paper and for containers. It also has potential value as an economical energy source in favourable situations. A stacked cord of air-dry wood ranges in heating value from 0.57 of a ton of coal (for aspen, Populus tremuloides) to 1.12 (for red maple, Acer rubrum) (Panshin et al. 1950). (A cubic metre of stacked wood of those species would equal 0.15 and 0.28 of a metric ton of coal, respectively).

Energy. We already face a serious worldwide problem of petroleum scarcity. Petroleum resources are strictly limited, and the life of the resource can be measured in terms of decades (Committee on Resources and Man 1969). Since the problem of energy is likely to become one of the first of the serious scarcity problems, let us consider what 
the impact on forest industries will likely be and how these may be accommodated.

In the past, many forest industries in remote areas were practically self-sufficient in power, using small local hydro sources (often owned by the company itself), power from steam boilers heated by waste wood, and in certain instances in the USSR by large-scale extraction of producer gas. If power is to become extremely expensive in the future, many forest industries could revert to this type of operation and gain some control over their power costs.

Prices of gasoline and diesel fuel are likely to rise drastically. What would happen to your particular logging operation if diesel fuel and gasoline increased $500 \%$ in price? Such increases are not unlikely. One must also remember that in the construction of machinery of all sorts, energy enters as a cost in a thousand different ways. In an energy-scarce age cost of all machinery and technological processes will rise sharply.

The changes in logging and milling techniques in recent decades resulted mostly from substitution of cheap energy for manpower. If, in the future, people become more common and energy more expensive, there may well be a turning point when it will be economically feasible to revert to labourintensive operations that consume less energy. With the application of present technology many older methods, such as river drives, logging railways, and skidding by draft animals and cable systems could be made much more efficient, at a great saving of energy.

We are assured by many authorities on energy that one of the best future hopes of increasing the supply of energy lies in creating breeder nuclear reactors. Such reactors will probably be feasible within a few decades, providing electricity from outside sources at a relatively cheap rate for many years thereafter. We should also note that many qualified nuclear scientists are skeptical that nuclear generation of power on a massive scale can ever be made sufficiently safe to be acceptable. Ultimately, the build-up of radioactive wastes and waste heat would set another limit to growth. However, it outside power were available, many operations might then be converted from gasoline power to electrical power. Electrical power saws could be introduced, as might electrical motors to operate cable yarding systems.

Portable power might also be obtained from electrical generators operated by wood-burning boilers. Such boilers, as well as vehicles, could be powered by producer gas from wood residues (Panshin et al. 1950). If nuclear power proves unfeasible, foresters will be forced to greater improvisation to obtain energy for their operations from the forest itself.

Wood may again become an important source of energy for heating in areas near forests. Modern stoves and furnaces are available that extract over $90 \%$ of the heat energy available in wood. This is not the case with the traditional Canadian stove where $40 \%$ or more of the heat usually goes up the chimney.

Pollution. It is, of course, axiomatic that pollution from forest industries must be greatly reduced in the very near future although one result will be increased costs of forest products. We have already made considerable reductions in pollution as we presently perceive it, although total elimination would probably be prohibitively expensive. We can provide an example to other industries by making our own operations, whether harvesting, manufacturing or transporting of forest products largely self-contained and non-polluting.

Population. All predicitions suggest that one of the greatest problems the world faces is the exponential increase in population. The increase will undoubtedly continue for some time. I have watched the population of Canada double in the period between my grade school years and my middle thirties. At that rate of increase, Canada would have a population of over $300,000,000$ before the year 2100 ! Such a population would obviously be far more than could be accommodated in a country that really has a rather small proportion of its area as food-producing land. The pollution and pressure on resources, even in a large well-watered nation, by a population of that size using our technology would reach unendurable levels. However, reductions in rates of growth will not come easily and we must expect some growth with its accompanying pressure on foresters and forest land.

The effect of those pressures will be to force a greater degree of multiple land use. Much more land will also be needed for recreation, more attention will have to be paid to the appearance of all lands in order to satisfy many more people wishing to live in a pleasant landscape. We must also consider the possibility that many of our better soils will be lost to forest production because of the need to produce more food. We may see a return of the subsistence type of agriculture throughout forested areas, even far to the north of places where agriculture is currently conducted. Another possibility that appears feasible is game ranching in conjunction with forestry to produce protein as well as wood from forest lands.

Recycling. Paper may be recycled perhaps two or three times. Then the worn fibres can be used for making wallboard (either a completely wooden product or, as in one experimental study, a board incorporating both waste plastic materials and wood) or for other uses.

As most of us are aware from our home activities, lumber can be recycled. It should be possible to develop systems for collecting, remanufacturing and recycling all kinds of wood materials. Of course one of the first problems of the forest industry in the age of scarcity would be to ensure that all parts of the tree and all species of trees, possibly even some shrubs, were utilized. As other materials become more costly present cost restraints on such utilization may be expected to disappear. 


\section{Planning for scarcity}

Time frame. The authors of Limits to Growth believed that we must decide now on methods of coping with the problem of scarcity. We have perhaps ten or fifteen years to plan the level of economic activity we are to shoot for in the future, and we should be taking steps now to stabilize the Canadian population because several decades will be required to effect such stabilization. Boyle, and also the Resources and Man Committee, believed that we have somewhat more time, but that definite action must be taken soon. Our entire life-style must be drastically changed during the next 50 to 75 years. By then a state of economic equilibrium must have been achieved. The urgent need for action means that we must begin to plan and assess our position now, accelerating necessary research and system monitoring.

The research and development challenge. The problems of scarcity suggest some new directions in research related to forestry and forest products and intensification of some present ones, such as: 1/ Improving wood burning equipment for homes and for larger buildings, with associated systems of harvesting, processing, transporting and storing fuelwood.

2/ Intensifying basic research in wood technology aimed toward utilization of all parts of all species, and on the ecological implications of of such utilization.

3/ Pilot projects in wood product development. Wood can replace non-renewable metals for many purposes.

4/ New methods of distributing electrical power at low voltages from main transmission lines to worksites that would be more flexible and economical than traditional pole lines.

5/ Improving compact producer gas units for vehicle propulsion.

6/ Research and development activities in relation to control of pollution at all levels of the forest industry. That research is, of course, now in progress and will increase.

7/ Intensifying studies of means to increase forest productivity, coupled with research on the ecological impact of the methods employed.

8/ Multiple land use research. Intensified basic research is required on the nature of land surface resources and social demands on land, possibly including pilot project studies in such fields as game ranching, alternative logging systems, landscape design and the interpretation of forest management activities to the public. The last is important because we cannot afford, at this stage, to have forest and land management encased in a legal straightjacket because of public misunderstanding.

\section{Conclusion}

I believe that foresters and the forest industries can contribute greatly to the relief of the worldwide scarcity problem facing mankind. I also believe that the forestry profession can make a significant intellectual contribution toward solving the resource dilemma. Foresters, by the nature of their education and of the resource with which they work, must consider what will happen at least one rotation in the future, often well over a century. We should try to impress on the "now" generation that such long-term planning is feasible. We foresters have a unique training for thinking in terms of an equilibrium state. The model of the normal forest a concept upon which we all dwell at great lengths during our training in forest management - represents an equilibrium state. Few other professionals in our society study such models. Therefore, we ought to be better equipped than most other professional groups to conceive of a steady state economy and its implications.

Foresters are compelled by the nature of the resource with which they work to adjust to an ultimate limit to economic growth. Once all of a forest has been placed under intensive management, including thinning, fertilization, better stocking with genetically improved strains and manipulation of rotations, and all parts of all species are in use, possible increases in yield are small. To paraphrase an ancient proverb, we are forced to cut our forest industry coat to fit our forest resource cloth.

In consideration of the above points, I believe that we have the intellectual tools to enable us to be leaders in the movements toward change in the world system. We should inform ourselves, then become active in prodding our fellow citizens toward the change of attitude that will lead to progress in coping with future scarcities. If we fail to act we may not only fail our fellow citizens in the broader sphere but be forced as well to watch control of the land resource pass to less well-trained hands.

\section{Literature cited}

BOYLE, T. J. 1973. Hope for the technological solution. Nature, 245 (21 Sept.) 127-128.

COMMITTEE ON RESOURCES AND MAN, NATIONAL ACADEMY OF SCIENCES - NATIONAL RESEARCH COUNCIL. 1969. Resources and man. W. H. Freeman and Co., 259 p.

MEADOWS, D. H., D. L. MEADOWS, J. RANDERS and W. H. BEHRENS III. 1972. The limits to growth. Universe Books. New York. 205 p.

PANSHIN, A. J., E. S. HARRAR, W. J. BAKER and P. B. PROCTOR. 1950. Forest products. 1st ed. McGraw-Hill Book Co., New York. 540 p. 